\title{
Cuvier's gazelle in Algeria
}

\author{
Koen de Smet
}

Cuvier's gazelle Gazella cuvieri is endemic to North Africa and has been classified as Endangered by IUCN. Algeria holds most of the remnant population but little is known about its current status and distribution there. The author studied the gazelle between 1984 and 1988 and found that while populations have declined in some areas, at least 560 individuals survive, some in protected areas.

\section{Introduction}

The edmi or Cuvier's gazelle Gazella cuvieri is a North African endemic, with its distribution limited to Morocco (including the Western Sahara), Algeria and Tunisia (Figure 1), although De Beaux (1928) and Hufnagl (1980) believed that it also once existed in north-eastern Libya. We knew very little about the species in Algeria; it was considered to be rare, but no information was available about its numbers. The IUCN (1974) classified the species as Endangered and believed that Algeria held most of the remnant population. In addition, almost nothing was known about its whereabouts and its habitat preferences.

\section{Methods}

This survey was conducted in Algeria between 1984 and 1988. During this period I visited nearly all areas in northern Algeria

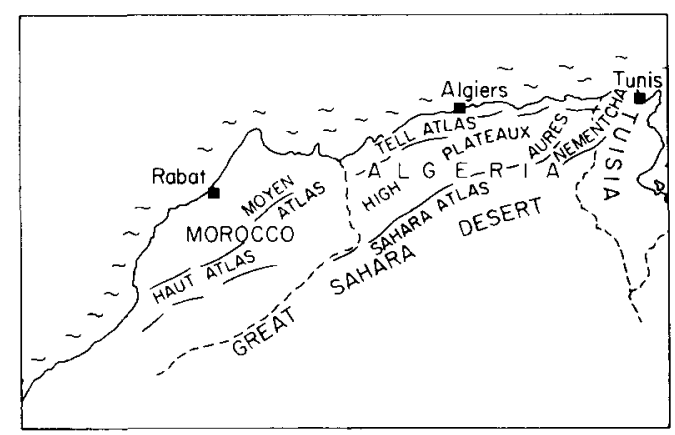

Figure 1. Map showing distribution of Cuvier's gazelle. where gazelles had been reported by a national survey undertaken by the Algerian Forest Service in 1983 or by other reliable persons. In all cases the habitat was described, the area searched for tracks and latrines, and local people were questioned to gain some idea of group size and habits of the animals. Furthermore, the regions where no information was available but which were situated within the geographical and ecological limits of the species, were explored. Maps of north Algeria were also examined for localities whose names referred to gazelles.

\section{Past distribution}

In the past Cuvier's gazelle was recorded from the southern slopes of the Tell Atlas Mountains, the Sahara Atlas Mountains and from hills and mountains in the eastern part of the country (Tristam, 1860; Loche, 1867; Pease, 1896; Joleaud, 1929; Heim de Balsac, 1936). In the 1960s Dupuy (1964, 1967) explored the semi-desert areas in the west of the country and mapped the presence of gazelles south of Bechar and north-east of that town in the Sahara Atlas. Petrov (1971), basing his information on a national game survey carried out by the Algerian Forest Service, found that in the west of the country gazelles were also present in the northern part of the Atlas Mountains. Many old Arabic names of places west of Algiers, even near the coast, incorporate references to gazelles and we must conclude that in the past the species must have 
been rather widespread. Past distribution records are shown in Figure 2.

\section{Current distribution}

Our investigations revealed that the current distribution (June 1989) does not differ substantially from the one given by Petrov (1971) (Figure 2). In the north-west the species is far more widespread than formerly believed. Nearly all the vast state forests of Aleppo pine Pinus halepensis have small populations and there is contact between most of these. They are also quite common in the hills between Mascara, Relizane, Tiaret and Frenda, living there in open country with a mixture of wheat fields, vineyards and hill-top grasslands. They have even been seen occasionally in the plains near the Chelif river, where in 1984 near El Asnam (now Ech Chelif), they damaged melon fields and were consequently killed. From this and other information (Gaucher, 1981) we know that when these gazelles were more abundant they came down from the mountains in the summer to graze and drink in the cultivated Chelif plains.

In the Sahara Atlas mountains, between Bechar and Biskra, most of the highest and undisturbed peaks still have some scattered groups of gazelles, the most important occurring near Djelfa (Khirreddine, 1977). The most recent information from the local forest service shows that the populations near Bou Saada are now increasing.

The easternmost populations are found in the Aures Mountains, the Nementcha Mountains and the hills near the Tunisian border. There is a major concentration of gazelles near Tebessa, these animals being associated with Djebel Chambi National Park in Tunisia.

There are only a few localities from which Cuvier's gazelle has disappeared in recent years and they are mostly in the northern part of its range. The populations of the western Tell Atlas and of Batna-Biskra and the Aures Mountains are no longer contiguous, and local groups in the Sahara Atlas have been slaughtered. However, the gazelles are very mobile here and could recolonize areas where they

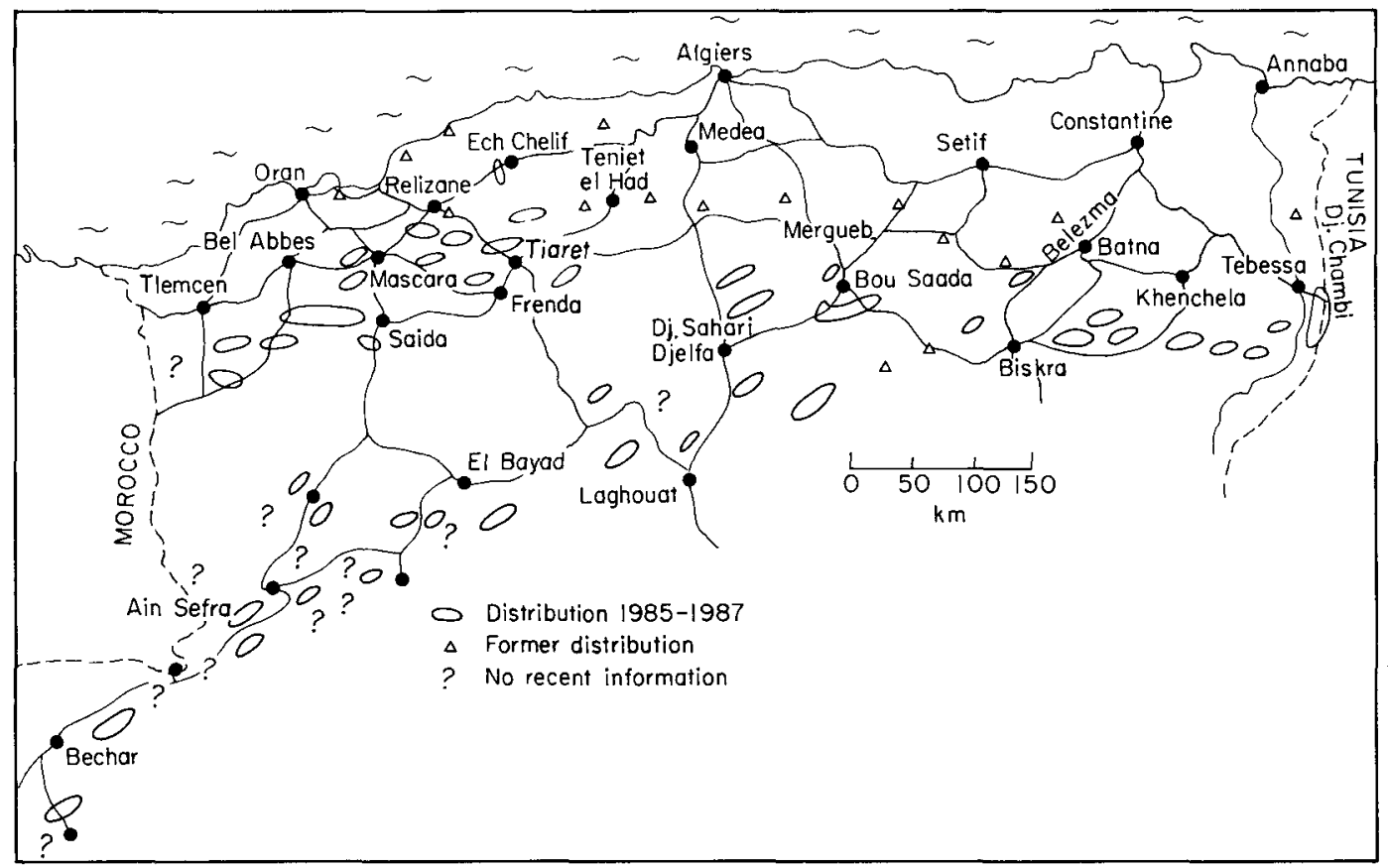

Figure 2. Map showing past distribution records of Cuvier's gazelle. 


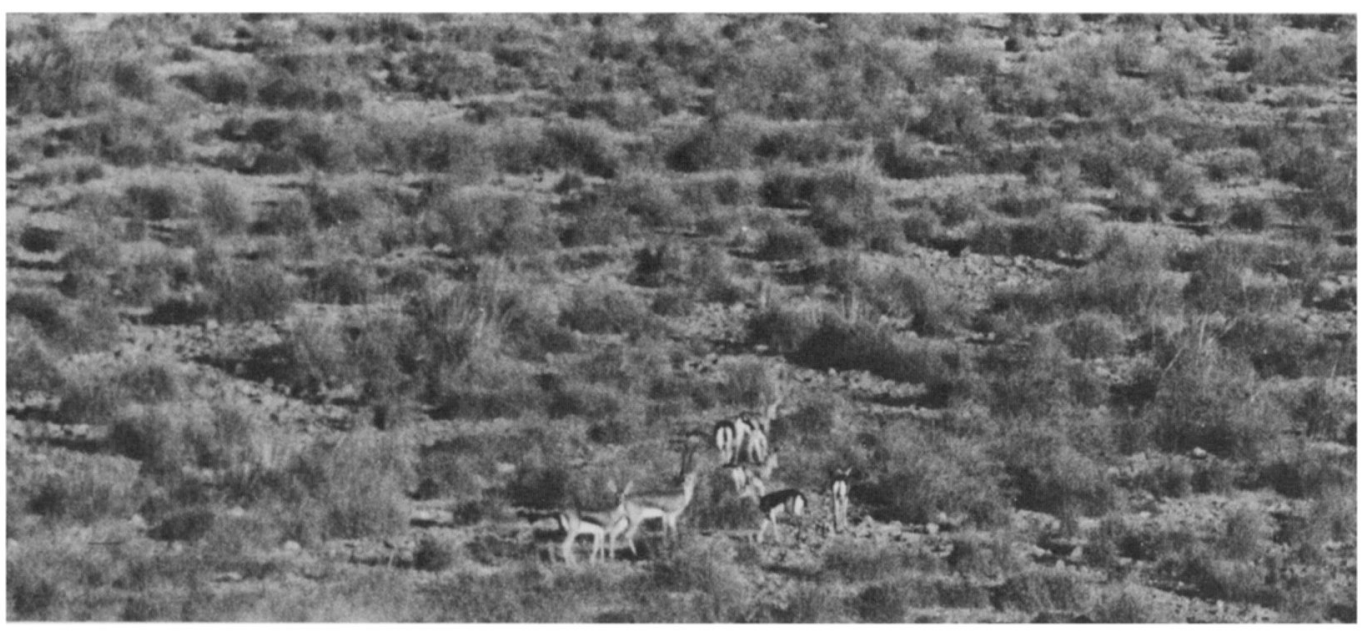

One male, three female and three juvenile Cuvier's gazelles among the alfa grass tufts of the Mergueb Nature Reserve (K. de Smet).

have been eradicated. The species is known to have reappeared near Theniet el Had and Tebessa after many years of absence.

Table 1. Distribution and numbers of Cuvier's gazelle in Algeria

\begin{tabular}{llr}
\hline 1. & Sidi Bel Abbes-Tlemcen-Telagh & 50 \\
2. Saida & 20 \\
3. Mascara-west & 20 \\
4. (a) Tiaret-Frenda-Tighenif & 100 \\
& (b) Dj. Nador & 30 \\
5. Ouarsenis mountains & 15 \\
6. El Bayad-Brezina & 10 \\
7. Aflou-Laghouat & 10 \\
8. Ain Sefra-El Abiod Sidi Cheikh & 10 \\
9. Bechar-Taghit & 20 \\
10. Djebel Senalba (Djelfa) & 30 \\
11. Djebel Sahari hunting reserve (Djelfa) & 20 \\
12. Guelt es Stel & 10 \\
13. Mergueb nature reserve & 50 \\
14. Bou Saada & 20 \\
15. Djebel Bou Kahil & 10 \\
16. Southern Aures & \\
& (incl. Beni Imloul and Barika) \\
17. East of Biskra & 30 \\
18. Nementcha mountains & 15 \\
19. Tebessa Forests & 10 \\
Total & \\
Of which 235 Tell Atlas; 140 Saharan Atlas; 135 & \\
Eastern group; 50 Mergueb central group. & \\
\hline & & \\
\hline
\end{tabular}

\section{Numbers}

Censusing gazelles is very difficult, especially because most populations are now confined to the hills. It is only in a few areas that they can be counted, even with a spotting scope, and it is difficult to avoid double-counting. The species is territorial and every valley within the territory is marked with dung-heaps. When the animals are numerous the dungheaps are often marked more than once or even daily. This makes it easy to detect the presence of gazelles, even in those areas where tracks are hard to find and sightings are only occasional because of tree cover.

Because we knew the numbers of gazelles and densities of latrines in some areas (forests in Saida and arid grassland north of Bou Saada), we could correct the numbers given by the forest service guards because we found that there was a relationship between the number of latrines and population densities. Unfortunately it proved very difficult to express this mathematically (Talbi, 1985).

We found that, generally, numbers in forests were underestimated but that we missed most gazelle groups in mountain areas such as the Sahara Atlas Mountains. Here local herdsmen were our main source of information.

Our estimated total of 560 Cuvier's gazelles in Algeria (Table 1) might be an underestimate, 
because there might be other populations still to be found, especially in the southern part of its range. Even though gazelle numbers may have risen in the last few years, the IUCN estimate of 200-300 in 1974 is definitely too low, even for that period. Lescomplekt (1989) suggested that there could be 200 in fields near Tiaret, but this seems rather high; our own studies in this region found that gazelles are very mobile in this area and it is easy to double-count.

\section{Habitat preferences}

The gazelle's range stretches from open oak forests in the Mascara region, $50 \mathrm{~km}$ from the Mediterranean, to desert on the hamadas (stony plateaux) near Bechar, which indicates that habitat requirements vary widely. North of Mascara there is a mixture of cork oak Quercus suber and holm oak $Q$. ilex. The annual rainfall is about $600 \mathrm{~mm}$, the altitude $700-800 \mathrm{~m}$, and snow is usual in winter. However, due to overgrazing, the vegetation is not dense. A $100 \mathrm{~km}$ further east, near the Teniet el Had National Park, the species lives in even more humid conditions and in the last century was rather common on the edge of the cedar forests at $1800 \mathrm{~m}$. Here too grazing pressure was high and the forests were never very dense. Many gazelles live in and around the wheat fields on the hills between Mascara, Frenda, Tiaret and Relizane. As in all Mediterranean landscapes where wheat has been grown for centuries, the topsoil of the hills has been washed away and now they are either covered with wild herbs or open maquis. This gives the gazelles sufficient shelter from human disturbance.

The southern parts of the Tell Atlas, where most of the gazelles live, are covered with Aleppo pine forests. The hills have been overgrazed for centuries and the forests are mainly open as a result. There are patches of regenerating forest, open areas where annual herbs grow and some heavily eroded barren patches. In the open forests the understorey species are Quercus ilex, Q. coccifera and Phylleria spp., while the most common herbs are Globularia spp. and Rosmarinus spp. The dominant grass

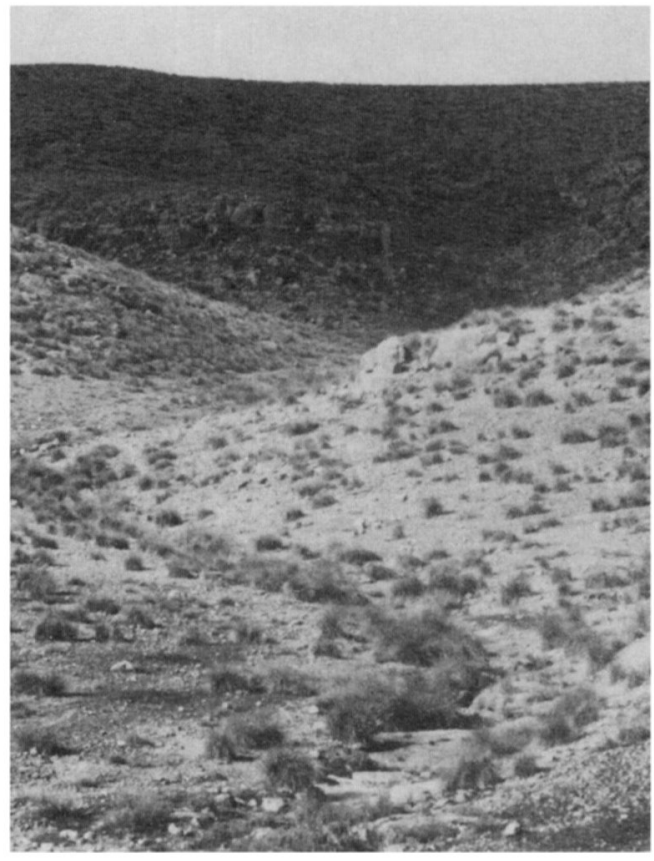

Canyons in the Mergueb reserve provide good cover, but make censusing difficult (K. de Smet).

is alfa or halfa Stipa tenacissima. To the south Stipa becomes more important and the pine cover diminishes. Water is only absent or rare in July-August. Normally the gazelles spend the day in the hills, descending to the valleys to graze at night or in the early morning. This forest type is to be found in the Tlemcen-Bel Abbes-Saida region, Djelfa, the southern slopes of the Aures Mountains and the Tebessa area, where the Barbary stag Cerous elaphus barbarus also occurred in the southern part of its range.

On the High Plateaux, Aleppo pine is almost completely absent and alfa grass becomes dominant. Around the salt lakes and on shallow soils members of the Chenopodiaceae are common, and Artemisia herba alba covers large areas. The hill tops were once covered with Aleppo pine, but it has completely disappeared and only Juniperus phoenicia remains. Other shrub species are Rhus tripartitus and Lycium arabicum on the hill slopes and Zizyphus lotus and Pistacia atlantica on the plains. The annual rainfall is about $150-250 \mathrm{~mm}$ and the average altitude is over $1000 \mathrm{~m}$.

The forests of the Sahara Atlas are much 
drier (200-250 $\mathrm{mm}$ rainfall) and have suffered severely from overgrazing and erosion. It is only around Djelfa and south of Bou Saada that forests are now quite well managed and protected. They occur at altitudes of 1250-1600 $\mathrm{m}$. The herb and shrub flora are similar to that of the pine forests of the southern Tell Atlas.

\section{Protection}

The species was officially protected in Algeria in 1975, but poaching continued and many animals were still hunted for pleasure or for acquiring trophies to sell. A stuffed gazelle is worth over 1000 dinars (\$US200) on the black market and in 1982 I saw two beautiful males for sale in the tourist market of Biskra. Nearly all wild animals have been protected since 1983 and possession or sale of stuffed animals is now forbidden.

People, even tribesmen living far away from towns and police stations, are very well aware that gazelle hunting is banned and this makes poaching less open, which increases the survival of small relict populations.

Hunting Cuvier's gazelle is more difficult than hunting other gazelles because the rocky tree-covered habitat enables the animals to hide quickly. Moreover, the possession of rifles is forbidden in Algeria so the hunters have to get very close for a kill.

In the north most gazelles occur within the limits of state forests, which gives their habitat protection. In the Sahara Atlas and on the High Plateaux, desert encroachment is increasing rapidly and in these zones habitat destruction may lead to the extermination of all wild animals.

The species occurs in two protected areas. The Djebel Sahari Hunting Reserve, which like other hunting reserves is considered a breeding centre for game animals and where all hunting is forbidden, is covered with Aleppo pine forests and open grassland. Some 200 families keep sheep within the $300-\mathrm{sq}-\mathrm{km}$ area, which is surrounded by a $2-\mathrm{m}$ high fence. Although the reserve has a high carrying

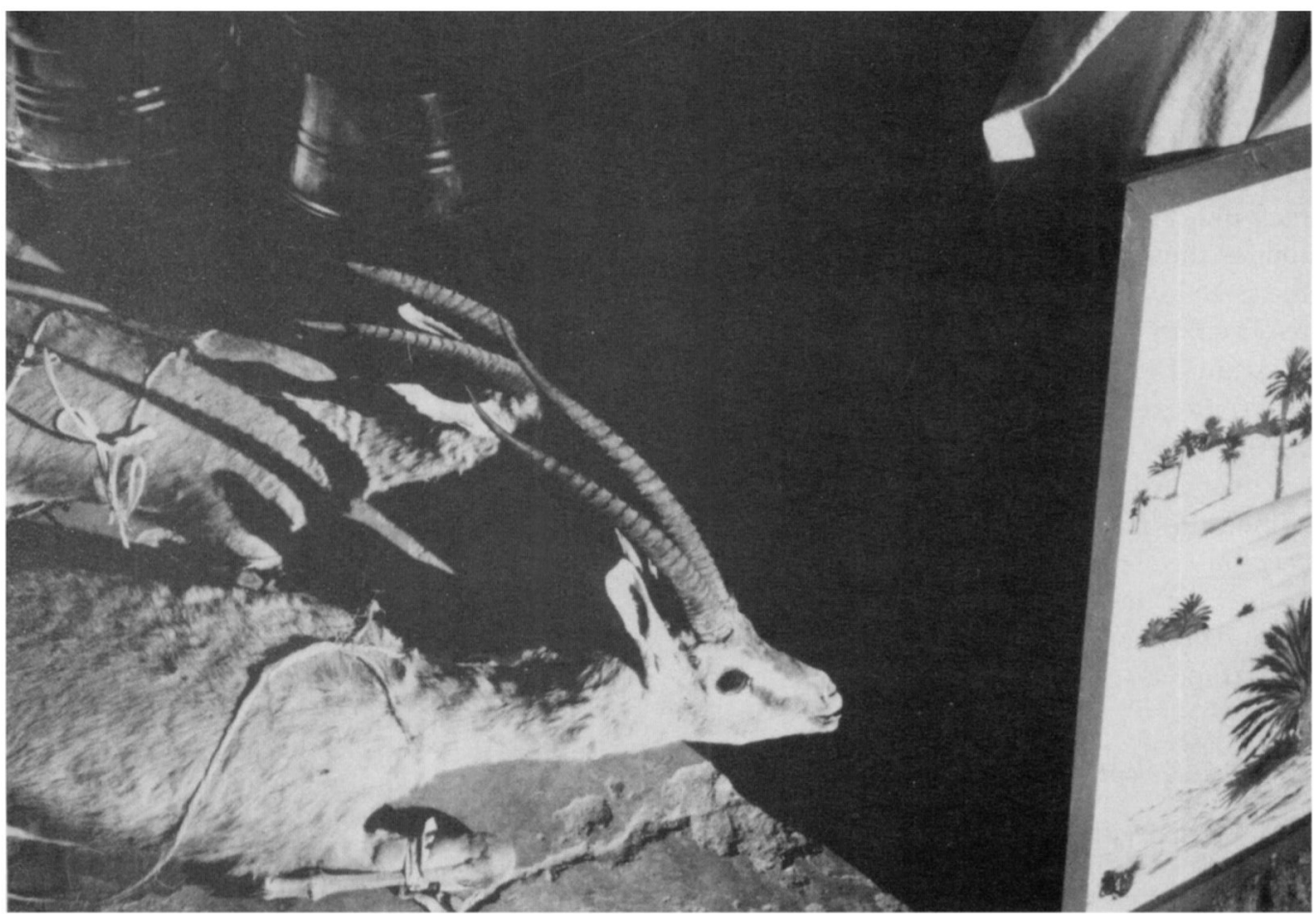

Stuffed males on the tourist markets: now forbidden and severely repressed (K. de Smet). 
capacity, the number of gazelles remains extremely low because of poaching.

The Mergueb Nature Reserve, on the High Plateaux about $60 \mathrm{~km}$ north of Bou Saada, is divided into two by the Algiers-Bou Saada highway. About 4000 ha are hilly with alfa grass predominating and 8000 ha are flat with Helianthemum lippii, Artemisia herba alba and Noaea mucronata each covering around 1000 ha. Over 1400 ha of Aleppo pine have been planted and on the hills there are several shrub species; the wild olive is heavily browsed by gazelles. Poaching has always been a problem and has particularly affected dominant males. Although each female gives birth to one young a year from the first year, and twins are sometimes born, numbers remained at around 50 for nearly 10 years. The reserve had no budget and the forest service had been neglecting it for years. It was only in 1989 that a director was appointed and the funds for management will now be provided by a nearby national park. I estimated the grazing capacity by various methods (De Smet, 1989) and found it to be higher than 1000 gazelles.

Reintroductions of Cuvier's gazelle are planned in the two national parks (Belezma and Teniet el Had). The fences and acclimatization pens are nearly complete but there will be a problem in catching enough gazelles from the wild. There is only one in captivity at present at the Algiers Zoo. In other state forests, the gazelle areas were declared local hunting reserves. In some cases-Djebel Nadour near Mascara, Djebel Ach near Saida and Bekkaria near Tebessa-these are or will be fenced.

Although there have been offers from the Spanish Arid Zones Research Centre in Almeria to provide some animals for reintroduction, we urge caution. The Spanish captive-reared animals originate from populations $2000 \mathrm{~km}$ away in the Western Sahara and they could be genetically very different.

\section{Acknowledgments}

This study and especially the field work, has only been possible with the co-operation and assistance of many forest officers and guards who are too numerous to thank individually. The English text has been revised by $\mathrm{S}$. Jenkinson, $\mathrm{H}$. Noble and V. Decock. Special help was received from Professor Kowalski, who provided old literature.

\section{References}

De Beaux, O. 1928. Risultate Zoologici della Missione di Giarabub (1926-1927). Mammiferi. Annal. Mus. Civ. Sto. Nat. Genova Giacomo Doria, 8, 183-217.

De Smet, K. 1989. Distribution and habitat choice of the larger mammals in Algeria with special reference to naure protection (in Dutch). PhD Thesis. State Univ. Gent, 357 pp.

Dupuy, A. 1964. La gazelle de Cuvier. Science et Nature , 65, 15-22.

Dupuy, A. 1967. Répartition actuelle des espèces menacées de l'Algérie. Bul. Soc. Sc. Nat. Phys. Maroc, 47, 329-354.

Gaucher, G. 1981. Traité de pédologie agricole; les facteurs de la pédogénèse. G. Lellotte-Dison, Brussels, Belgique.

Heim de Balsac, H. 1936. Biogéographique des mammifères et des oiseaux de l'Afrique du Nord. Bull. Biol. France-Belg. Suppl. 21, 1-447.

Hufnagl, E. 1980. Report of an extended visit of two weeks at the Kouf National Park (Libya). Mimeo, $18 \mathrm{pp}$.

IUCN. 1974. Red data book sheet: Gazella cuvieri.

Joleaud, L. 1929. Etudes de la géographique zoologique sur la Berbérie. Bull. Soc. Zool. France., LIX, 438-457.

Khirreddine, A. 1977. Etude écologique pour un aménagement cynégétique dans le massif Senalba Chergui à Djelfa. Thèse Ir. Agr. I.N.A. El Harrach, $113 \mathrm{pp}$.

Lescomplekt. 1989. Exposé sur le projet d'inventaire du gibier en Algérie du Nord. Mimeo, 30 pp.

Loche, V. 1867. Exploration scientifique de l'Algérie 1840-41-42. Histoires naturelles des mammifères. Sciences physiques, Zoologie, 1-123.

Pease, A. E. 1896. On the antilopes of the Aures and the Eastern Algerian Sahara. Proc. Zool. Soc. London, 809-814.

Petrov, P. 1971. Repartition du gibier en Algérie et mesures à prendre en vue de la conservation et son développement. Rapport polyc. Dir. Forets, 18 pp. \& 21 pp. en annexe.

Talbi, K. 1985. Inventaire du gibier en vue d'un aménagement cynégétique de la foret $d^{\prime}$ Oum Graf (Saida). Thèse Ir. Agr. I.N.A. El Harrach, 80 pp.

Tristam, H.B. 1860. The Great Sahara. Wanderings South of the Atlas Mountains. John Muray, London.

Koen de Smet, Delftstraat 4, 2200 Borgerhout, Belgium. 